\title{
LYMPHOID ORGANS IN EXPERIMENTAL PROSTATE CARCINOGENESIS
}

\section{Andrey Lomshakov ${ }^{1 凶}$, Vadim Astashov² (D), Oleg Zayko², llya Pushkar²}

\author{
${ }^{1}$ LLC MC Stolitsa, Moscow, \\ 2 Peoples Friendship University of Russia (RUDN University), Moscow, \\ Russia
}

a.lomshakov@gmail.com

\begin{abstract}
Histological methods were used to study structural changes in the thymus and pelvic lymph nodes of SVA mice on day 18 after transplantation of ascitic Ehrlich tumor into the prostate gland. On day 18 of the experiment, a complete replacement of normal tissue with atypical cells, disorganization of the thymus structure - an increase in the volume of cortical matter, the number of epithelial reticular cells, a decrease in the number of immunoblasts in the cortical and cerebral matter was found. In the lymph nodes, on day 18 , metastases were determined, follicular reaction was detected, increased transport function, against the background of an increase in the number of lymph vessels in the prostate.
\end{abstract}

KEYW ORDS - thymus, pelvic lymph nodes, prostate tumor.

\section{INTRODUCTION}

Carcinogenesis disrupts the stages of the immune response and its consistency. The thymus undergoes involution, $\mathrm{t}$-cell immunodeficiency is formed. Generalization of carcinogenesis-metastasis of tumor cells into lymph nodes. The state of pelvic lymph nodes in prostate cancer is a significant factor in the prognosis of disease [1], and the detection of micrometastases in lymph nodes is the most important task in the stage of prostate cancer [2]. The study of the Central and peripheral organs of the lymphoid system during transplantation induction of carcinogenesis, reveals changes in their structure depending on the stage of carcinogenesis, the dynamics of metastasis in the lymphatic system, which will assess the effect of known and new anti-tumor drugs.

\section{PURPOSE}

Identification of structural transformations of the thymus and regional lymph nodes in various experimental prostate tumors.

\section{MATERIALS AND METHODS}

We used 60 Mature male SVA mice weighing up to $30 \mathrm{~g}$ (Institute of Cytology and genetics SB RAS,
Novosibirsk). The experiment was performed according to "Rules of works using experimental animals", approved by order of Ministry of health of the USSR №577 of 12.08.1977, principles of humanity set out in European community Directive (86/609/EC).An experimental model of a malignant prostate tumor was created (under ether anesthesia) by inoculation of a diluted cell strain of ascitic Ehrlich carcinoma into the organ parenchyma: $0.2 \mathrm{ml}$ of ascitic fluid containing $500-550 \cdot 10^{3}$ cells was injected. A tumor node was formed in the prostate from polymorphic atypical cells [3]. Experimental groups: 1) intact; 2) animals on the $18^{\text {th }}$ day of experimental prostate tumor growth. Animals were removed from the experiment by dislocation of cervical vertebrae under ether anesthesia. For histological examination, the prostate, thymus, pelvic lymph nodes were taken, with fixation in Tellesnitsky's solution. From the material in paraffin, longitudinal slices ( 5 and 7 microns) were made, stained with hematoxylin-eosin according to Mayer and AzurIIEOSIN according to Nocht-Maksimov. At magnification of 16, 32, 200 and 1000 times the method of point counting was used to perform morphometry of sections and counting of cell elements of the above described organs according to International histological terminology. The results were processed by methods of variational statistics, determined the reliability of differences using the student's criterion. $\mathrm{P}<0.05$ was considered reliable.

\section{RESULTS AND DISCUSSION}

On the $18^{\text {th }}$ day of tumor growth, complete replacement of prostate tissue with atypical polymorphic cells (tumor parenchyma $-82.3 \pm 0.6 \%$, tumor stroma $-17.7 \pm 0.4 \%$ ) of oval, elongated or polygonal shape with hyperchromic nuclei was revealed. $\mathrm{Nu}$ clear cytoplasmic cell index $1.66 \pm 0.08$. In the thymus, cortical matter increased by $8 \%$, the area of connective tissue structures - by $29 \%$, glandular epithelial formations - by 2.8 times. Areas of brain matter decreased by $16 \%$ compared to the same value in the group of intact animals. The number of Gassal bodies and the size of glandular epithelial formations increased in comparison with the control values. In all areas of the thymus decreased the number of small lymphocytes, cells at the stage of mitosis, macrophages, immunoblasts, against the background of growth of epithelial reticular cells and medium lymphocytes, in comparison 
with the control group. The exception was the corticomedullary zone, in which the number of immunoblasts increased (Table 1). son with the control values, as well as the number of epithelial reticular cells. According to the literature, glandular epithelial formations of the thymus are

Tab. 1. Relative sizes of structural and functional zones of the thymus in normal and experimental tumor growth in the prostate $(M \pm m)(\%)$

\begin{tabular}{l|l|l}
\hline Structural and functional zones & Intact animals & $18^{\text {th }}$ day of experimental prostate tumor growth \\
\hline Cortical substance & $58,45 \pm 1,65$ & $63,12 \pm 0,79^{*}$ \\
\hline Brain substance & $34,76 \pm 1,37$ & $29,15 \pm 0,41^{*}$ \\
\hline Cortical-brain index & $1,68 \pm 0,05$ & $2,16 \pm 0,03^{*}$ \\
\hline Connecting-woven elements & $6,75 \pm 0,17$ & $7,61 \pm 0,2^{*}$ \\
\hline Area of glandular formations & $0,04 \pm 0,02$ & $0,11 \pm 0,05$ \\
\hline Parenchymal/stromal ratio & $13,8 \pm 0,4$ & $12,1 \pm 0,16^{*}$ \\
\hline
\end{tabular}

* These differences are significant in comparison with control animals at $P<0.05$.

By the $18^{\text {th }}$ day-in the marginal and cerebral sinuses of the pelvic lymph nodes, tumor metastases were detected - atypical large cells with pronounced polymorphism (stage II). In comparison with the control group, the area of the paracortical zone increased by $20 \%$. The size of the brain cords decreased by $3 \%$, the B-dependent zone - by $7 \%$. The area of the brain sinuses-decreased by $9 \%$. In germinative centers of lymphoid nodules, in comparison with those in the control group, the number of immunoblasts (from $7.68 \pm 0.36$ to $11.65 \pm 0.54$ ) increased by $35 \%$, the number of macrophages increased by $28.5 \%$ (from $4.29 \pm 0.25$ to $6.0 \pm 0.37$ ). In the brain strands-there was an increase in average lymphocytes (from $6.55 \pm 0.27$ to $21.18 \pm 0.79$ ) by $3-4$ times and a decrease in the number of Mature plasmocytes by $34 \%$ (from $44.17 \pm 0.81$ to $28.26 \pm 0.91$ ). The number of macrophages increased by $30 \%$ - from $3.46 \pm 0.21$ to $4.89 \pm 0.32$ (Table 2).

\section{CONCLUSIONS}

Malignant tumors produce substances that reduce or block the antitumor immune response [8]. By suppressing the local immune response, the tumor suppresses immune organs that reduce the production of immunocompetent cells or produce defective cytotoxic lymphocytes, which serve as a source of immunosuppressive T-reg cells $[9,10]$. Thymus involution and disturbance of peripheral t-lymphocyte replenishment underlie the development of T-cell immunodeficiency in carcinogenesis [11]. Prostate tissue is completely replaced by atypical cells (18 days), with a decrease in blood vessels in the stroma of the tumor. In these terms of carcinogenesis in the thymus - the $2^{\text {nd }}$ phase of accidental involution [13]. The relative area of glandular epithelial formations increases in compari- functional structures that enhance the secretion of its hormones under extreme effects on the body [12]. The experimental data duplicate the data of other authors - the growth and formation of a malignant tumor leads to accidental involution of the thymus and is a consequence of antigenic stimulation [3], and immunosuppressive action of vascular endothelial growth factor (VEGF) [14]. When metastases appear in the marginal and cerebral sinuses of lymph nodes, the structural organization changes and their transport function is disturbed. In the cortical substance of lymph nodes, structural signs of inferiority of the local immune response were revealed - a decrease in the area of the paracortical (T-dependent) zone, an increase in the size of the B-dependent zone, a nodular reaction. In the brain substance of lymph nodes there is a reaction to metastasis - a reduction in the size of the brain sinuses, which is characteristic of the late stages of carcinogenesis.

\section{REFERENCES}

1. BerEzhNAYA N.M., CheKhUN V.F.. Immunology of malignant growth. / Kyiv: Naukova Dumka, - 2005.$790 \mathrm{p}$.

2. Alekseev B. Ya, Rusakov I. G, Frank G. A. ET AL. determination of watchdog lymph nodes in patients with prostate cancer // Ross. onkol. Journ.2006. - No. 5. - P. 16-22.

3. Harisinghani M.G., Barentsz J., Hahn P. F. eT AL. Noninvasive detection of clinically occult lymphnode metastases in prostate cancer / N New Engl. J. Med. - 2003. - Vol. 348. - №25. - P. 2491-2499. DOI: $10.1056 /$ NEJMoa022749

4. Astashov V. V., Lomshakov A. A., Larionov P. M., ET AL. Lymph nodes and vessels in experimental tumors of the prostate // Vestnik NSU; ser. Biol. 2011, - Vol. 9, - №2. - P. 118-125. 


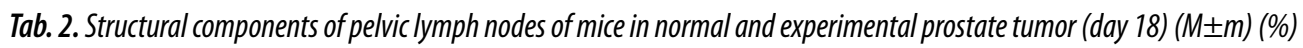

\begin{tabular}{l|l|l}
\hline Structural components & Intact animals & 18 th day of experimental prostate tumor growth \\
\hline Secondary lymphoid nodules & $4,39 \pm 0,16$ & $4,3 \pm 0,09$ \\
\hline Germinative center & $1,62 \pm 0,21$ & $1,2 \pm 0,09$ \\
\hline Mantle zone & $2,77 \pm 0,17$ & $3,1 \pm 0,16$ \\
\hline Primary lymphoid nodules & $3,6 \pm 0,2$ & $1,82 \pm 0,15^{*}$ \\
\hline Interstitial zone & $2,63 \pm 0,21$ & $1,82 \pm 0,15^{*}$ \\
\hline Paracortical zone & $19,5 \pm 0,47$ & $27,23 \pm 1,55^{*}$ \\
\hline Brain cords & $46,0 \pm 0,86$ & $44,64 \pm 1,67$ \\
\hline Brain sinuses & $18,54 \pm 1,2$ & $15,21 \pm 0,92$ \\
\hline Edge sine & $2,29 \pm 0,21$ & $1,91 \pm 0,2$ \\
\hline Capsule & $2,87 \pm 0,21$ & $2,45 \pm 0,18$ \\
\hline Trabeculas & $0,19 \pm 0,09$ & $0,6 \pm 0,12$ \\
\hline Cortical substance & $30,1 \pm 0,83$ & $35,18 \pm 0,8^{*}$ \\
\hline Brain substance & $64,54 \pm 1,58$ & $59,85 \pm 1,25$ \\
\hline B-dependent zone & $56,6 \pm 0,53$ & $52,59 \pm 1,24$ \\
\hline Cortical $\backslash$ brain index & $0,47 \pm 0,01$ & $0,59 \pm 0,02$
\end{tabular}

* These differences are significant in comparison with control animals at $P<0.05$.

5. LILLY R. Pathological technique and practical histochemistry. M.: World, 1969. - 646 p.

6. Sarkisov D. S., Perov Yu. L. Microscopic technique $-544 \mathrm{p}$.

7. Lapach S. N., Chubenko, L. V., Babich P. N. Statistical methods in biomedical studies using Excel. Kiev: MORION, 2001. - 408 p.

8. Whiteside T.L. The role of immune cells the tumor microenvironment // Cancer Treatm. Res. - 2006. - Vol. 130. - P. 103-124. DOI: 10.1007/0-387-26283$0 \_5$

9. Mailloux A.W., Young M.R. Regulatory T-cell trafficking: from thymic development to tumorinduced immune suppression // Crit. Rev. Immunol. 2010. - Vol. 30. - №5. - P. 435-447. PMID: 21083525

10. Stewart T. J., Smyth M.J. Improving cancer immunotherapy by targeting tumor-induced immune suppression / Cancer Metastasis Rev. - 2011. - Vol. 30. - №1. - P. 125-140. DOI:10.1007/s10555-0119280-5

11. Kiseleva E. P. Mechanisms of thymus involution in tumor growth. // Uspekhi sovr. Biology. - 2004. - Vol. 124. - P. 589-601.

12. Bodey B., Siegel S. E., KAISE H.E. Immunological Aspects of Neoplasia - The Role of Thymus. /Dordrecht: Boston: Kluwer Acad. Publ., - 2004 - 207 p. DOI : 10.1007/1-4020-2185-2

13. Ivanovskaya T.E, Zaretians O. V., LeONOva L. V., Voloshchuk I. N. Pathology of the thymus in children. / SPb. SOTIS, - $1996-270$ p.
14. Оhм J.E., Gabrilovich D.I., Sempowski G.D. ET AL. VEGF inhibits T-cell development and may contribute to tumor-induced immune suppression // Blood. - 2003. - Vol. 101. - P. 4878-4886. DOI: 10.1182/blood-2002-07-1956

15. Datta K., Muders M., Zhang H., Tindall D.J. Mechanism of limph node metastasis in prostate cancer // Future Oncology. - 2010. - Vol. 6, - №5. - P. 823-836 DOI:10.2217/fon.10.33. 